\title{
Mixture of Embryonal and Alveolar
} Features Present

National Cancer Institute

\section{Source}

National Cancer Institute. Mixture of Embryonal and Alveolar Features Present. NCI

Thesaurus. Code C121662.

A morphologic finding indicating the presence of a mixture of embryonal and alveolar components in a rhabdomyosarcoma. 